growth of the intestine of the suckling rat and on the development of intestinal alkaline phosphatase and disaccharidase activities. J. Exp. Zool., 200: 337 (1977).

27. Charles River Labs, Cambridge, MA

28. Brinkman Instruments, Westbury, NY

29. Kontes Glass Col, Vineland, NJ.

30. New England Nuclear. Boston, MA.

31. Beckman Instrument Co. Palo Alto CA

32. The present address of Dr. Warshaw is: Department of Pediatrics, Universitv of Texas, Southwestern Medical School, 5323 Harry Hines Blvd., Dallas, Texas 75235 .

33. Requests for reprints should be addressed to: Dr. Robert E. Kimura, Depart ment of Pediatrics, University of Utah School of Medicine, $50 \mathrm{~N}$. Medical ment of Pediatrics, University of
Dr., Salt Lake City, Utah 84132.

34. This research was supported by NIH grant no. 1-R23 HD 16908-01

35. Received for publication December 30, 1982

36. Accepted for publication September 22, 1983

\title{
Effects of Meclofenamate on Pulmonary Vascular Resistance Correlate with Postnatal Age in Young Piglets
}

\author{
GREGORY J. REDDING, ${ }^{(26)}$ IVAN MCMURTRY, AND JOHN T. REEVES \\ Cardiovascular Pulmonary Research Laboratory, University of Colorado Health Sciences Center, \\ Denver, Colorado, USA
}

\begin{abstract}
Summary
We administered sodium meclofenamate, a prostaglandin synthetase inhibitor, to 15 piglets (ages 5-70 d) to test the hypothesis that endogenous prostaglandin pulmonary vasodilators influence total pulmonary resistance under both normoxic and hypoxic conditions. No significant differences in hemodynamic measurements were found between the control group and drug-treated animals more than 12-d-old. When six experimental animals less than $12 \mathrm{~d}$ of age were compared with six age-matched controls, meclofenamate produced a small but significant increase in mean pulmonary artery pressure $(110 \pm 9$ versus $97 \pm 10 \%, P<0.05)$ and total pulmonary resistance $(135 \pm 23$ versus $102 \pm 12 \%, P$ $<0.03$ ). The magnitude of the change in total pulmonary resistance produced by $2 \mathrm{mg} / \mathrm{kg}$ of meclofenamate during normoxia correlated inversely with postnatal age $(r=0.83, P<0.01)$. Individual changes in pulmonary hemodynamics produced by acute hypoxia after meclofenamate treatment were the same as pretreatment values and were similar in both young and older animals.
\end{abstract}

Prostaglandin compounds produce either vasoconstriction of dilation of the pulmonary circulation when administered to adult and neonatal animals $(5,7,11,17,18,20)$. The importance of endogenous prostaglandin production in the regulation of pulmonary vascular tone under normoxic and hypoxic conditions is less clear as data from previously reported studies are somewhat conflicting. For example, Tyler et al. (22) found that pulmonary vascular resistance increased after inhibition of prostaglandin production by indomethacin during both normoxia and acute exposure to hypoxia in newborn goats. Lock et al. (12) found an increase in pulmonary vascular tone under normoxic conditions within minutes after indomethacin was administered intravenously but not when given orally to $2-4$-wk-old lambs. In contrast, Weir et al. (24) found no changes in pulmonary artery pressure during normoxia after intravenous administration of meclofenamate to 2-4-mo-old calves. We administered sodium meclofenamate, a prostaglandin synthetase inhibitor (3), to newborn piglets to further test the hypothesis that endogenous prostaglandin pulmonary vasodilators influence total pulmonary vascular resistance in newborns under both normoxic and hypoxic conditions. Our data indicate that total pulmonary resistance increased after meclofenamate treatment under normoxic conditions in animals less than 12-d-old and that this effect diminished with increasing postnatal age. In addition, we found that inhibition of prostaglandin synthesis had no effect upon hypoxic pulmonary vasoconstriction in piglets.

\section{MATERIALS AND METHODS}

Animal preparation. Thirty-three piglets, aged 5-88 d and weighing $1.75-25 \mathrm{~kg}$, were anesthetized with intravenous sodium pentobarbital $(15 \mathrm{mg} / \mathrm{kg})$, heparinized, and intubated. Each animal was mechanically ventilated using a Harvard small animal ventilator, adjusted to deliver a tidal volume of $15 \mathrm{cc} / \mathrm{kg}$ at a rate of 20-30 breath/min in order to maintain $\mathrm{PaCO}_{2} 37 \pm 5 \mathrm{~mm} \mathrm{Hg}$; positive end-expiratory pressure was maintained at $2 \mathrm{~cm} \mathrm{H}_{2} \mathrm{O}$. Arterial oxygen tensions were maintained at approximately 60 $\mathrm{mm} \mathrm{Hg}$ or more during normoxic conditions by supplementing inspired room air with $30 \% \mathrm{FiO}_{2}$ when necessary. Body temperature was monitored with a rectal probe (Yellow Springs Model 333 ) and was maintained at $38.5 \pm 0.7^{\circ} \mathrm{C}$ using heating lamps to approximate the temperatures of awake uninstrumented piglets.

A polyethylene catheter was placed in the descending aorta via the left internal carotid artery for blood pressure recordings and arterial blood sampling. A second catheter was inserted into the superior vena cava via the left external jugular vein for injections of green dye and drug administration. A double-lumen balloontipped catheter was placed in the left branch of the pulmonary artery via the right external jugular vein under fluoroscopy to measure pulmonary artery pressure. Inflation of the balloon frequently produced pulmonary hypertension or systemic hypotension, and consequently, pulmonary capillary wedge pressure was measured during only 11 of 27 experiments. Heart rate and 
mean pulmonary and systemic artery pressures were measured continuously using Statham PD3 transducers. Arterial blood gas tensions, $\mathrm{pH}$, and cardiac output by the green dye dilution technique were measured intermittently, using a Radiometer blood gas analyzer and Water Instruments cuvette densitometer respectively. Cardiac output determinations required withdrawal of $5 \mathrm{ml}$ of blood past the densitometer with a heparinized syringe using a Harvard infusion pump. Heart rate and mean pulmonary and systemic artery pressures did not change during repeated measurements suggesting that serial measurements of cardiac output per se did not alter the animals' hemodynamic states. Pressure measurements were recorded in digital form every $30 \mathrm{~s}$ and cardiac output measurements were calculated throughout the experiment using a NOVA 2000 computer (4).

Prostaglandin synthesis inhibition. In order to demonstrate that $2 \mathrm{mg} / \mathrm{kg}$ of meclofenamate inhibited prostaglandin synthesis, hemodynamic measurements were made in six piglets, 5-16$\mathrm{d}$-old, during infusions of $100 \mu \mathrm{g} \cdot \mathrm{kg}^{-1} \cdot \mathrm{min}^{-1}$ of arachidonic acid. In three of these animals (ages 5, 13, and $16 \mathrm{~d}$ ) measurements were recorded under normoxic conditions after infusing arachidonate for $5 \mathrm{~min}$ before and $45 \mathrm{~min}$ after treatment with meclofenamate. Paired $t$ tests were used to determine if the changes after meclofenamate were significant.

Protocol. In another 13 piglets (3-70-d-old) hemodynamic, blood gas tension, and $\mathrm{pH}$ measurements were made initially during room air ventilation and after $5 \mathrm{~min}$ of acute isocapnic hypoxia, produced by administering $12 \% \mathrm{FiO}_{2}$. A single intravenous bolus of $2 \mathrm{mg} / \mathrm{kg}$ of sodium meclofenamate dissolved in saline was administered, and hemodynamic measurements were repeated after an interval of 45 min during normoxic conditions and after $5 \mathrm{~min}$ of hypoxia.

A control group of 11 piglets, aged 5-88 d, entered the same protocol but received saline instead of meclofenamate. Hemodynamic measurements were made during normoxia but not hypoxia before and after meclofenamate or saline in three additional animals during preliminary experiments and these data have been incorporated in the results.

Data analysis. Total pulmonary resistance $\left(\overline{\mathrm{P}}_{\mathrm{PA}} / \mathrm{CO}\right)$ and total systemic vascular resistance $\left(\overline{\mathrm{P}}_{\mathrm{SD}} / \mathrm{CO}\right)$ were calculated from each set of hemodynamic measurements made during normoxia and hypoxia before and after the administration of meclofenamate or saline. To determine individual responses to meclofenamate, each animal's hemodynamic values before and after receiving the drug during normoxia were expressed as ratios, i.e., posttreatment value/pretreatment value. Hemodynamic changes produced by acute hypoxia were also expressed as ratios, e.g., hypoxic value/normoxic value, in order to compare hypoxic pulmonary pressor responses before and after meclofenamate or saline treatment.

Differences between the meclofenamate-treated group and the control group during several periods of ventilation with room air and hypoxia were assessed using a one-way analysis of variance and a Dunnett's test of multiple comparisons. (2) The significance of correlations between drug-induced hemodynamic changes and postnatal age were determined using a Student's $t$ test. $P<0.05$ was considered significant.

\section{RESULTS}

Intravenous infusions of $100 \mu \mathrm{g} \cdot \mathrm{kg}^{-1} \cdot \mathrm{min}^{-1}$ of arachidonate under normoxic conditions increased pulmonary artery pressure by $31 \pm 30 \%$ and total pulmonary resistance by $35 \pm 23 \%$ without changing cardiac output in six piglets, 5-16 d of age. Forty-five minutes after meclofenamate was administered to three of the piglets, arachidonic acid increased mean pulmonary artery pressure by $9 \pm 3 \%$ and total pulmonary resistance by 3 $\pm 5 \%$ (Fig. 1). The diminished response to arachidonate after meclofenamate treatment was statistically significant (paired $t$ test, $P<0.05$ ).

Table 1 lists the hemodynamic values for the 27 additional piglets, aged 5-86 d, measured under normoxic conditions before
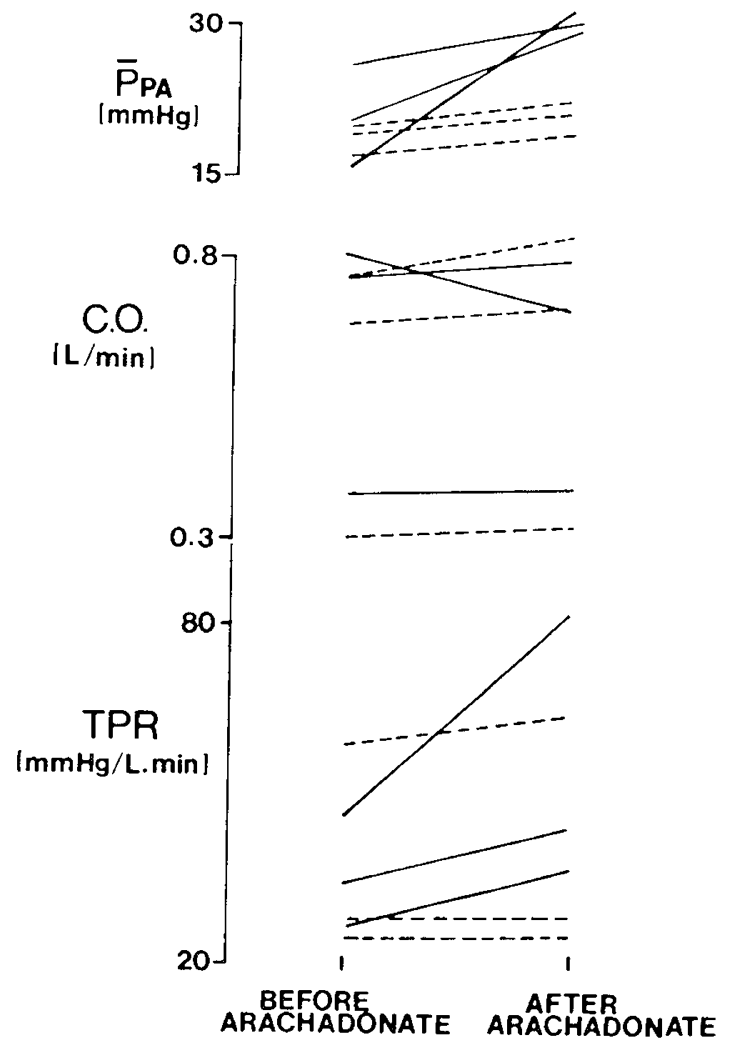

Fig. 1. Pulmonary hemodynamic response to arachidonic acid infusion during normoxia before and after meclofenamate treatment in three piglets, 8-14-d-old. Solid and dashed lines represent changes produced by arachidonic acid before and after meclofenamate treatment, respectively. Mean pulmonary artery pressure $(\overline{\mathrm{P}} \mathrm{PA})$ rose $10 \pm 3 \mathrm{~mm} \mathrm{Hg}$ during arachidonate infusion before meclofenamate and $2 \pm 1 \mathrm{~mm} \mathrm{Hg}$ after treatment. Total pulmonary resistance (TPR) during the infusion rose $39 \pm 20 \mathrm{~mm} \mathrm{Hg} \cdot \mathrm{L}^{-1} \cdot \mathrm{min}^{-1}$ before meclofenamate and $2 \pm 2 \mathrm{~mm} \mathrm{Hg}$. $\mathrm{L}^{-1} \cdot \mathrm{min}^{-1}$ after treatment. Cardiac output (C.O.) did not change before or after meclofenamate treatment.

and after receiving $2 \mathrm{mg} / \mathrm{kg}$ of meclofenamate or saline. Pretreatment arterial blood gas tensions were similar to those measured after meclofenamate or saline administration in all animals. Arterial oxygen tensions were statistically similar in both control and meclofenamate-treated animals in all age groups. Mean $\mathrm{PaCO}_{2}$ and $\mathrm{pH}$ pretreatment values were similar in control and meclofenamate-treated groups $\left(\mathrm{PaCO}_{2}, 39 \pm 5\right.$ versus $37 \pm 5 \mathrm{~mm}$ $\mathrm{Hg}$ and $\mathrm{pH}, 7.42 \pm 0.06$ versus $7.45 \pm 0.04)$ and did not change after drug treatment. $\mathrm{PaCO}_{2}$ and $\mathrm{pH}$ were also similar in the young compared with the older piglets.

Cardiac output values before treatment for the 27 animals correlated with increasing body weight and postnatal age. Consequently, calculated total pulmonary resistance and systemic vascular resistance during normoxia were lower in older animals compared with the younger piglets (Table 1). When individual hemodynamic responses to $2 \mathrm{mg} / \mathrm{kg}$ meclofenamate during normoxia were expressed as ratios of post-treatment values/pretreatment values, no significant differences were found between the older control group and drug-treated animals more than 12-dold. When the six experimental animals less than $12 \mathrm{~d}$ of age were compared to the six age-matched control animals, meclofenamate produced a small but significant increase in both mean pulmonary artery pressure $(110 \pm 9$ versus $97 \pm 10 \%, P<0.05)$ and total pulmonary resistance $(135 \pm 23$ versus $102 \pm 12 \%, P$ $<0.03)$. Cardiac output fell after administration of meclofenamate more than after saline administration in the younger animals $(84 \pm 14$ versus $100 \pm 17 \%)$, but this difference was not statistically significant. The magnitude of the change in total pulmonary resistance produced by $2 \mathrm{mg} / \mathrm{kg}$ of meclofenamate 
Table 1. Hemodynamic measurements in newborn and older piglets during normoxia before and after meclofenamate or saline*

\begin{tabular}{|c|c|c|c|c|c|c|c|c|c|}
\hline & $n$ & $\begin{array}{l}\text { Body Wt } \\
(\mathrm{kg})\end{array}$ & $\begin{array}{c}\overline{\mathrm{P}}_{\mathrm{PA}} \\
(\mathrm{mm} \mathrm{Hg})\end{array}$ & $\begin{array}{c}\overline{\mathrm{P}}_{\mathrm{SA}} \\
(\mathrm{mm} \mathrm{Hg})\end{array}$ & $\begin{array}{c}\overline{\mathrm{P}}_{\mathrm{CW}} \ddagger \\
(\mathrm{mm} \mathrm{Hg})\end{array}$ & $\begin{array}{l}\text { Cardiac output } \\
(\mathrm{L} / \mathrm{min})\end{array}$ & $\begin{array}{c}\text { TRP } \\
(\mathrm{mm} \mathrm{Hg} \\
\left.\mathrm{L}^{-1} \cdot \mathrm{min}^{-1}\right)\end{array}$ & $\begin{array}{c}\mathrm{TSR} \\
(\mathrm{mm} \mathrm{Hg} \\
\left.\mathrm{L}^{-1} \cdot \mathrm{min}^{-1}\right)\end{array}$ & $\begin{array}{c}\mathrm{PaO}_{2} \\
(\mathrm{~mm} \mathrm{Hg})\end{array}$ \\
\hline \multicolumn{10}{|l|}{ 5-12-d-old piglets } \\
\hline Before meclo & 6 & $2.4 \pm 0.8$ & $16 \pm 1 \dagger$ & $73 \pm 12$ & $5 \pm 1$ & $0.46 \pm 0.21$ & $45 \pm 22 \dagger$ & $196 \pm 102$ & $74 \pm 11$ \\
\hline After meclo & & & $19 \pm 2$ & $71 \pm 5$ & $5 \pm 1$ & $0.37 \pm 0.17$ & $60 \pm 25$ & $226 \pm 92$ & $74 \pm 11$ \\
\hline Before saline & 6 & $2.6 \pm 0.7$ & $19 \pm 4$ & $87 \pm 10$ & $6 \pm 1$ & $0.52 \pm 0.22$ & $39 \pm 12$ & $175 \pm 68$ & $77 \pm 15$ \\
\hline After saline & $\ldots$ & $\ldots$ & $18 \pm 5$ & $86 \pm 12$ & $7 \pm 2$ & $0.50 \pm 0.23$ & $43 \pm 14$ & $186 \pm 59$ & $71 \pm 11$ \\
\hline \multicolumn{10}{|c|}{ 13-20-d-old piglets } \\
\hline Before meclo & 6 & $5.7 \pm 3.7$ & $19 \pm 3$ & $93 \pm 16$ & $6 \pm 1$ & $1.21 \pm 0.66$ & $19 \pm 8$ & $90 \pm 30$ & $75 \pm 19$ \\
\hline After meclo & & & $20 \pm 4$ & $103 \pm 32$ & $7 \pm 2$ & $1.29 \pm 0.76$ & $19 \pm 8$ & $95 \pm 24$ & $76 \pm 19$ \\
\hline Before saline & 3 & $6.3 \pm 4.4$ & $16 \pm 8$ & $100 \pm 17$ & $6 \pm 1$ & $1.45 \pm 0.83$ & $12 \pm 4$ & $82 \pm 21$ & $83 \pm 19$ \\
\hline After saline & $\ldots$ & $\ldots$ & $16 \pm 3$ & $103 \pm 20$ & $7 \pm 2$ & $1.50 \pm 1.06$ & $12 \pm 5$ & $83 \pm 33$ & $89 \pm 9$ \\
\hline \multicolumn{10}{|c|}{ 55 -88-d-old piglets } \\
\hline Before meclo & 3 & $15.1 \pm 2.7$ & $20 \pm 10$ & $119 \pm 13$ & $\ldots$ & $2.22 \pm 0.73$ & $10 \pm 7$ & $58 \pm 21$ & $67 \pm 14$ \\
\hline After meclo & & & $19 \pm 10$ & $118 \pm 8$ & $\ldots$ & $2.56 \pm 1.01$ & $9 \pm 7$ & $53 \pm 26$ & $65 \pm 13$ \\
\hline Before saline & 3 & $20.8 \pm 7.6$ & $18 \pm 8$ & $111 \pm 8$ & $\ldots$ & $3.59 \pm 1.55$ & $5 \pm 3$ & $34 \pm 12$ & $67 \pm 14$ \\
\hline After saline & $\ldots$ & $\ldots$ & $14 \pm 5$ & $109 \pm 9$ & $\ldots$ & $3.30 \pm 0.88$ & $4 \pm 2$ & $35 \pm 13$ & $66 \pm 8$ \\
\hline
\end{tabular}

$* \bar{x} \pm \mathrm{SD}$ or individual measurements. Abbreviations: $\overline{\mathrm{P}}_{\mathrm{PA}}$, mean pulmonary arterial pressure; $\overline{\mathrm{P}}_{\mathrm{SA}}$, mean systemic arterial pressure; $\overline{\mathrm{P}}_{\mathrm{CW}}$, mean pulmonary capillary wedge pressure; TRP, total pulmonary resistance; and TSR, total systemic resistance.

$\dagger$ Significant difference between pre- and post-treatment values, $P<0.05$.

$\ddagger \bar{P}_{\mathrm{CW}}$ was measured in three control and two experimental piglets less than 12-d old; and four experimental and two control animals 13-20-d old.

during normoxia significantly correlated in an inverse exponential fashion with postnatal age for the 15 piglets which received the drug (Fig. 2).

Pulmonary capillary wedge pressure was similar in six experimental and five control animals and did not change after meclofenamate or saline administrations. Furthermore, there was no change in this measurement in young or older animals after meclofenamate treatment (Table 1).

Hemodynamic values before and after 5-min exposures to hypoxia in young and older piglets before and after treatment with meclofenamate are listed in Table 2. Under hypoxic conditions, pulmonary artery pressures and total pulmonary resistances approximately doubled compared with normoxic values in every meclofenamate-treated animal. But the individual changes in cardiac output, mean pulmonary and systemic artery pressure, heart rate, and calculated total pulmonary resistance and systemic vascular resistance produced by acute hypoxia after meclofenamate treatment were the same as the pretreatment values in 13 piglets (Fig. 3). The degree of hypoxic pulmonary vasoconstriction after meclofenamate was also similar to that after saline administration in 11 control animals. The magnitude of acute hypoxic pulmonary vasoconstriction before and after meclofenamate treatment was similar in both the young and older animals and did not correlate with postnatal age.

\section{DISCUSSION}

Meclofenamate competitively binds to cyclooxygenase, the enzyme which produces prostaglandin intermediates which are then converted to either prostaglandin pulmonary vasodilators or vasoconstrictors $(3,8)$. It is approximately $60 \%$ more potent than indomethacin and 300 times more potent on a weight-toweight basis than aspirin in inhibiting the production of prostaglandin intermediates (3). In previous studies, intravenous administration of $1-2 \mathrm{mg} / \mathrm{kg}$ of meclofenamate has abolished the efflux of prostaglandin compounds by the kidney (13). To document the effectiveness of prostaglandin synthesis inhibition in intact newborn piglets, the pulmonary vascular response to arachidonic acid, which is the substrate for cyclooxygenase and precursor for all prostaglandin compounds, was measured before and after meclofenamate treatment. Arachidonate infusions in concentrations of more than $50 \mu \mathrm{g} \cdot \mathrm{kg}^{-1} \cdot \mathrm{min}^{-1}$ increase pulmonary artery pressure and pulmonary vascular resistance in awake sheep and anesthetized neonatal goats $(14,21)$. Those same effects in our animals were reduced by 71 and $90 \%$, respectively,

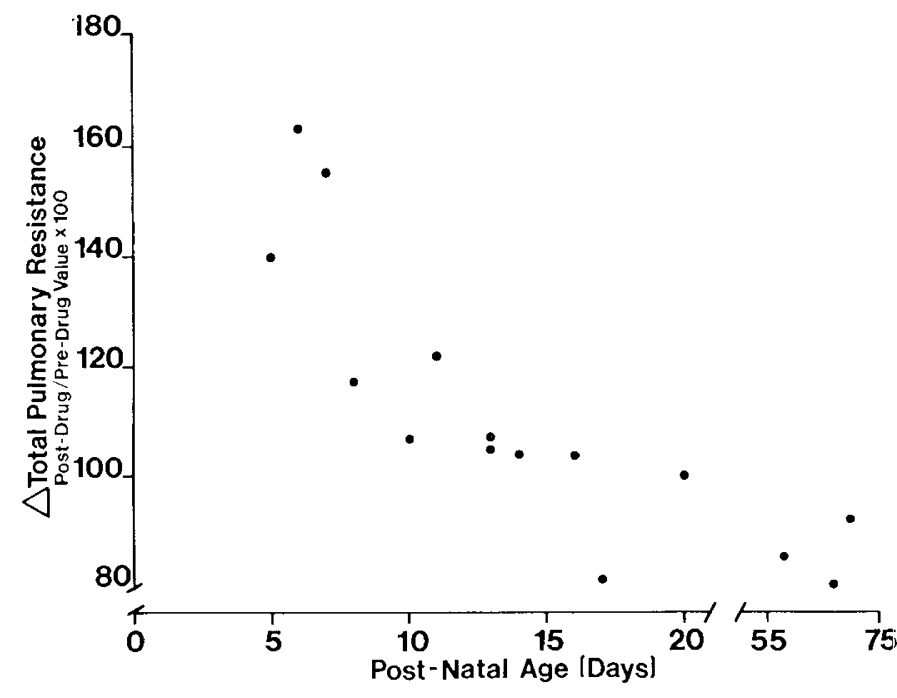

Fig. 2. Changes in total pulmonary resistance produced by $2 \mathrm{mg} / \mathrm{kg}$ of meclofenamate relate to postnatal age under normoxic conditions. " 100 " represents no change after treatment compared with pretreatment values $(r=0.83, P<0.01)$.

after meclofenamate treatment, demonstrating the effectiveness of this prostaglandin synthesis inhibitor in both young and old piglets.

Meclofenamate reduces the amount of precursor common to all prostaglandin compounds rather than influencing the enzymes that synthesize individual prostaglandins. Changes, therefore, in the pulmonary hemodynamics after meclofenamate treatment reflect diminished production of the predominant prostaglandins, either dilators or constrictors, which most influence pulmonary vascular resistance. We found that meclofenamate produced vasoconstriction during normoxia in piglets less than $12 \mathrm{~d}$ of age but did not alter pulmonary hemodynamics in older animals. These results suggest that vasodilator prostaglandins influence pulmonary vascular tone more than prostaglandin vasoconstrictors during normoxia in newborn piglets, but that the predominance of prostaglandin vasodilators becomes less pronounced with age.

An alternative explanation for our results would include increased synthesis of leukotrienes from endogenous arachidonic 
Table 2. Hemodynamic values during acute hypoxia before and after meclofenamate treatment*

\begin{tabular}{|c|c|c|c|c|c|c|}
\hline & $\begin{array}{c}\overline{\mathrm{P}}_{\mathrm{PA}} \\
(\mathrm{mm} \mathrm{Hg})\end{array}$ & $\underset{(\mathrm{mm} H \mathrm{Hg})}{\overline{\mathrm{P}}_{\mathrm{SA}}}$ & $\begin{array}{l}\text { Cardiac output } \\
(\mathrm{L} / \mathrm{min})\end{array}$ & $\begin{array}{c}\mathrm{TPR} \\
\left(\underset{\mathrm{mm} \mathrm{Hg} \cdot \mathrm{L}^{-1}}{\left.\mathrm{~min}^{-1}\right)}\right.\end{array}$ & $\begin{array}{c}\mathrm{TSR} \\
\left(\mathrm{mm} \mathrm{Hg} \cdot \mathrm{L}^{-1}\right. \\
\left.\mathrm{min}^{-1}\right)\end{array}$ & $\begin{array}{c}\mathrm{PaO}_{2} \\
(\mathrm{~mm} \mathrm{Hg})\end{array}$ \\
\hline \multicolumn{7}{|c|}{$5-12$-d-old piglets $(n=5)$} \\
\hline \multicolumn{7}{|c|}{ Pre-Meclo } \\
\hline Normoxia & $17 \pm 1$ & $69 \pm 11$ & $0.39 \pm 0.18$ & $50 \pm 20$ & $211 \pm 106$ & $75 \pm 12$ \\
\hline Hypoxia & $38 \pm 6 \dagger$ & $91 \pm 22$ & $0.44 \pm 0.27$ & $118 \pm 66 \dagger$ & $276 \pm 149$ & $34 \pm 9 \dagger$ \\
\hline \multicolumn{7}{|l|}{ Post-Meclo } \\
\hline Normoxia & $19 \pm 2 \ddagger$ & $71 \pm 5$ & $0.33 \pm 0.14$ & $65 \pm 25 \ddagger$ & $243 \pm 89$ & $77 \pm 11$ \\
\hline Hypoxia & $39 \pm 10 \dagger$ & $94 \pm 20$ & $0.41 \pm 0.19$ & $114 \pm 50 \dagger$ & $267 \pm 94$ & $33 \pm 6 \dagger$ \\
\hline \multicolumn{7}{|c|}{ 13-70-d-old piglets $(n=8)$} \\
\hline \multicolumn{7}{|c|}{ Pre-Meclo } \\
\hline Normoxia & $16 \pm 8$ & $98 \pm 17$ & $1.36 \pm 0.66$ & $17 \pm 8$ & $84 \pm 30$ & $74 \pm 17$ \\
\hline Hypoxia & $38 \pm 6 \dagger$ & $109 \pm 38$ & $1.60 \pm 0.82$ & $30 \pm 15 \dagger$ & $92 \pm 41$ & $32 \pm 8 \dagger$ \\
\hline \multicolumn{7}{|l|}{ Post-Meclo } \\
\hline Normoxia & $19 \pm 6$ & $109 \pm 27$ & $1.48 \pm 0.79$ & $17 \pm 9$ & $87 \pm 27$ & $74 \pm 17$ \\
\hline Hypoxia & $36 \pm 7 \dagger$ & $116 \pm 47$ & $1.53 \pm 0.83$ & $30 \pm 15 \dagger$ & $103 \pm 46$ & $31 \pm 9 \dagger$ \\
\hline
\end{tabular}

* Data expressed as $\bar{x}+\mathrm{SD}$. Abbreviations: $\overline{\mathrm{P}}_{\mathrm{PA}}$, mean pulmonary arterial pressure; $\overline{\mathrm{P}}_{\mathrm{SA}}$, mean systemic arterial pressure; TPR, total pulmonary resistance; and TSR, total systemic resistance.

$\dagger$ Hypoxic value significantly different than normoxic value, $P<0.05$.

$\ddagger$ Normoxic value after meclofenamate significantly different than pretreatment normoxic value, $P<0.05$.

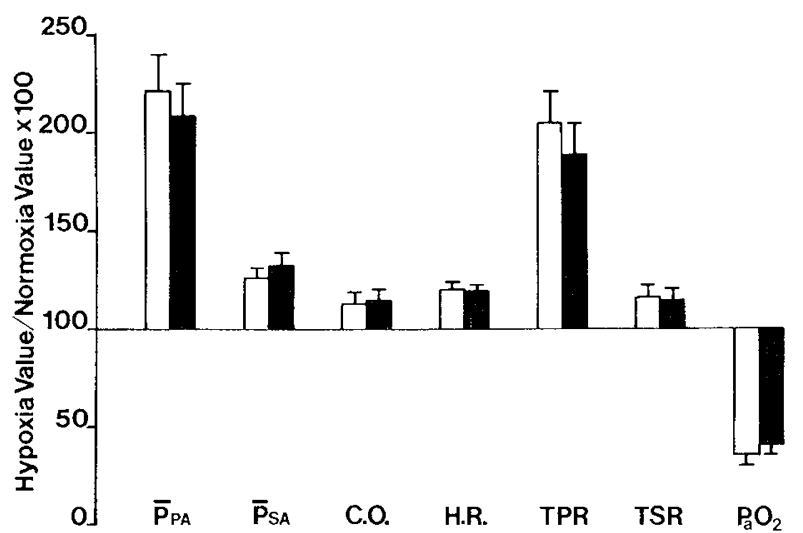

Fig. 3. Changes in pulmonary hemodynamics produced by acute isocapnic hypoxia before and after meclofenamate treatment. The individual hypoxic pressor responses of 13 piglets are expressed as ratios of hypoxic/normoxic values. "100" represents no change associated with hypoxia. $\square$, before meclofenamate and $\mathbf{m}$, after meclofenamate treatment. Values for the group are expressed as $\bar{x} \pm$ SEM. Abbreviations: $\overline{\mathrm{P}} \mathrm{PA}$, mean pulmonary artery pressure; $\overline{\mathrm{P}} \mathrm{SA}$, mean systemic arterial pressure, C.O., cardiac output; H.R., heart rate; TPR, total pulmonary resistance; and TSR, total systemic resistance.

acid stores through the lipoxygenase enzymatic pathway (15). If cyclooxygenase is inhibited by meclofenamate, endogenous arachadonic acid might be preferentially utilized to make leukotrienes, compounds which are known to produce pulmonary vasoconstriction when administered to newborn lambs (25). It is possible that preferential production of leukotrienes after cyclooxygenase inhibition by meclofenamate occurs most readily in the perinatal period and then diminishes with postnatal age. Such a phenomenon was not investigated in this study but remains a possibility consistent with our results.

When postnatal age is considered an important variable, our findings are consistent with data from several reports that heretofore, appeared contradictory. Leffler et al. (10) reported that inhibition of prostaglandin synthesis by indomethacin diminished the fall in pulmonary vascular resistance which accompanied ventilation during the first several hours after birth in newborn goats. In similar studies, indomethacin produced an $82 \%$ increase in pulmonary vascular resistance during normoxia in 1-d-old premature goats and a $26 \%$ increase in pulmonary vascular resistance in 6-d-old fullterm newborn goats (22). In contrast, Lock et al. (12) found that oral indomethacin given for $3 \mathrm{~d}$ to $10-12$-wk-old lambs produced no changes in the pulmonary vascular resistances under normoxic conditions. Finally, Weir et al. (24) found no changes in pulmonary artery pressures in 2-4-mo-old normoxic calves after intravenous administration of meclofenamate. These results as a group are consistent with the hypothesis that endogenous prostaglandin pulmonary vasodilators may be most important around the time of birth and become less influential determinants of pulmonary vascular resistance during normoxia with increasing postnatal age.

Other reports suggest that postnatal age is not the only variable determining the importance of endogenous prostaglandins as regulators of pulmonary vascular tone. Prostaglandin synthesis inhibition by meclofenamate in awake adult dogs produces a rise in pulmonary vascular resistance under normoxic conditions (23). Similarly, lobar pulmonary artery pressure increases in pump-perfused anethetized normoxic dogs after administration of indomethacin (6). In awake newborn lambs, $0.1 \mathrm{mg} / \mathrm{kg}$ of indomethacin injected into the left pulmonary artery produced a substantial but transient increase in pulmonary vascular resistance which diminished after $30 \mathrm{~s}$ and was completely gone by 5 min (12). The influence of prostaglandins on the pulmonary circulation appears to also depend upon the animal species and the experimental conditions and timing of hemodynamic measurements after inhibition of prostaglandin synthesis.

Inhibition of endogenous prostaglandin production did not alter the magnitude of acute hypoxic pulmonary vasoconstriction in young or older piglets. These results are similar to those reported in awake lambs and dogs $(12,23)$ but differ from results in calves, anesthetized dogs, and isolated rat lungs (24). In reports where prostaglandin inhibition augmented the pulmonary hypoxic pressor response, the statistically significant increases in pulmonary artery pressure after drug administration were 10 $19 \%$ in dogs and calves (24). In our experiments, the variability of hypoxic pulmonary vasoconstriction associated with multiple exposures to hypoxic gas in each individual piglet averaged $16 \pm$ $10 \%$. Small increases in hypoxic pulmonary vasoconstriction after meclofenamate treatment in piglets may have been similar in magnitude to previously reported results but obscured by the variability of each individual animal's response to hypoxia.

The endogenously produced prostaglandin pulmonary vasodilators, which may be most influential in newborns, have been 
characterized by others. Terrango et al. (19) reported that isolated fetal and neonatal vessels, including pulmonary arteries, produced prostaglandins $I_{2}$ and $E_{2}$ in greater quantities than did adult sheep vessels, and that prostacyclin $\left(\mathrm{PGI}_{2}\right)$ was the principle arachidonic acid metabolite produced by pulmonary vessels in newborns. Leffler et al. (9) reported increased pulmonary venous concentrations of a prostacyclin-like substance after the onset of ventilation in fetal goats and lambs. We speculate that endogenous prostaglandin pulmonary vasodilators, such as prostacyclin, have their greatest influence at the time of birth and become less influential as the newborn grows older. Furthermore, if persistent pulmonary hypertension of the newborn $(1,16)$ results in part from an abnormally slow synthesis or small influence of prostaglandin pulmonary vasodilators, the self-limited nature of this disorder among survivors of this syndrome may be explained by the progressively smaller influence of prostaglandins on pulmonary hemodynamics which appears to occur with increasing postnatal age.

\section{REFERENCES AND NOTES}

1. Brown, R. and Pickering. D.: Persistent transitional circulation. Arch. Dis. Child., 49: 883 (1974).

2. Dunnett. C. W.: New tables for multiple comparisons with a control. Biometrics, 20:482 (1964).

3. Flower, R. J. and Vane, J. R.: Commentary: inhibition of prostaglandin biosynthesis. Biochem. Pharmacol., 23: 1439 (1974).

4. Huber, F., Sodal, I. E., and Weil, J. V.: On-line cardiac output by digital computer. J. Appl. Physiol., 40: 266 (1976).

5. Kadowitz. P. J. Chapnick, B. M. Feigen, L. P., Hyman, A. L., Nelson, P. K. and Spannhake. E. W.: Pulmonary and systemic vasodilator effects of the newly discovered prostaglandin, $\mathrm{PGI}_{2}$. J. Appl. Physiol., 45: 408 (1980).

6. Kadowitz. P. J., Chapnick, B. M., Joiner, P. D., and Hyman, A. L.: Influences of inhibitors of prostaglandin synthesis on the canine pulmonary vascula bed. Am. J. Physiol., 229: 941 (1975).

7. Kadowitz, P. J., Joiner, P. D., and Hyman, A. L.: Influence of prostaglandins $\mathrm{E} 1$ and $\mathrm{F} 2 \alpha$ on pulmonary vascular resistance in sheep. Proc. Soc. Exp. Biol. Med., 145: 1258 (1974).

8. Lands, W. E.: The biosynthesis and metabolism of prostaglandins. Ann. Rev. Physiol. . 41: 633 (1979).

9. Leffler. C. W.. Hessler, J. R., and Terragno, N. A.: Ventilation-induced release of prostaglandinlike material from fetal lungs. Am. J. Physiol., 238: H282 (1980).

10. Leffler, C. W.. Tyler, T. L., and Cassin, S.: Effect of indomethacin on pulmonary vascular response to ventilation in fetal goats. Am. J. Physiol., 234: H346 (1978).
11. Lock. J. E., Olley. P. M., and Coceani, F.: Direct pulmonary vascular responses to prostaglandins in the conscious newborn lamb. Am. J. Physiol., 238: H631 (1980)

12. Lock, J. E.. Olley, P. M., Soldin, S., and Coceani, F.: Indomethacin-induced pulmonary vasoconstriction in the conscious newborn lamb. Am. J. Physiol., 238: H639 (1980).

13. Lonigro, A. J., Itsokovitz, H. D., Crowshaw, K., and McGiff, J.: Dependency of renal blood flow on prostaglandin synthesis in the dog. Circ. Res., 32: 712 (1973).

14. Ogletree, M. L. and Brigham, K. L.: Arachadonate raises vascular resistance but not permeability in lungs of awake sheep. J. Appl. Physiol., 48: 581 (1980).

15. Samuelsson, B.: The leukotricnes: an introduction. Adv. Prostaglan. Thrombox. Res. Lcuk. Res., 9: 1 (1982).

16. Siassi, B., Goldberg, S. J., Emmanouilides, G. C., Higashino, S. M., and Lewis, E.: Persistent pulmonary vascular obstruction in newborn infants. J. Pediatr 78: $610(1971)$.

17. Soifer, S. J., Morin, F. C., and Heymann, M. A.: Prostaglandin $D_{2}$ reverses induced pulmonary hypertension in the newborn lamb. J. Pediatr., 100:458 (1981).

18. Starling, M. B., Neutze, J. M., and Elliott, R. L.: Effects of prostaglandin E1. prostacyclin, and tolazoline on elevated pulmonary vascular resistance in neonatal swine. Adv. Prostaglan. Thrombox. Res.. 7: 755 (1980).

19. Terragno, N. A. and Terragno, A.: Prostaglandin metabolism in the fetal and maternal vasculature. Fed. Proc.. 38: 75 (1978).

20. Tyler, T., Leffler, C.. Wallis, R., and Cassin, S.: Effects of prostaglandins of the E-series on pulmonary and systemic circulations of newborn goats during normoxia and hypoxia. Prostaglandins, 10:963 (1975).

21. Tyler. T., Leffler, C., and Cassin, S.: Effects of prostaglandin precursors, prostaglandins, and prostaglandin metabolites on pulmonary circulation of perinatal goats. Chest (suppl.), 71: 271 (1977).

22. Tyler, T., Wallis, R., Leffler, C., and Cassin, S.: The effects of indomethacin on the pulmonary vascular response to hypoxia in the premature and mature newborn goat. Proc. Soc. Exp. Biol Med. 150:695 (1975)

23. Walker, B. R., Voelkel, N. F., and Reeves, J. T.: Pulmonary pressor response after prostaglandin synthesis inhibition in conscious dogs. J. Appl. Physiol. 52: 705 (1982).

24. Weir, E. K., McMurtry, I. F., Tucker, A., Reeves, J. T., and Grover, R. F Prostaglandin synthetase inhibitors do not decrease hypoxic pulmonary vasoconstriction. J. Appl. Physiol., 41: 714 (1976).

25. Yokochi, K., Olley, P. M., Sideris, E., Hamilton, F., Hashtanen, D., and Coceari. F.: Leukotriene $\mathrm{D}_{4}$ : a potent vasoconstrictor of the pulmonary and systemic circulations in the newborn lamb. Adv. Prostaglan. Thrombox. Res., Leuk. Res., 9: 211 (1982).

26. Requests for reprints should be addressed to: Dr. Gregory J. Redding, Box RD-20, Department of Pediatrics, University of Washington School of Medicine. Seattle, WA 98195

27. This research was supported by NIH grant HL 06006-01.

28. Received for publication September 3,1982.

29. Accepted for publication September 12, 1983. 